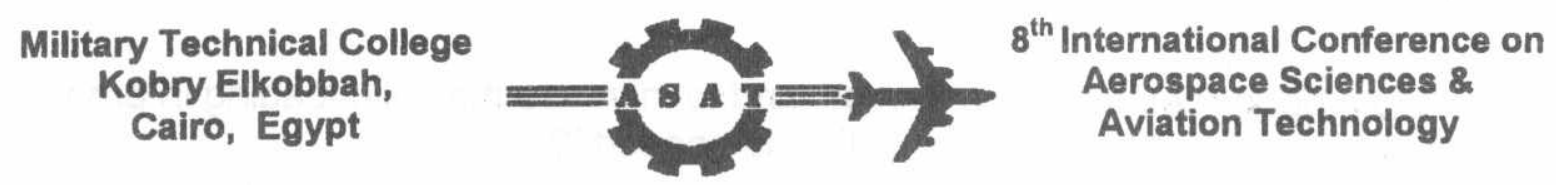

\title{
COMPARISON BETWEEN PARTICLE SIZE DISTRIBUTION OF HEXOGEN AND OCTOGEN DURING FORCED CRYSTALLIZATION
}

\author{
M.A.SADEK ${ }^{*}$
}

\begin{abstract}
Advanced solid rocket propellants with a low-pressure exponent and minimum signature comprise high- energy nitramine compounds such as hexogen and octogen. To achieve the desired processing conditions and increase the solid loading, the nitramine explosives are required with different grain size. The control of growth rate of crystals of nitramines by stirring, cooling and by crystal habit modifiers has been studied. The influence of these factors on crystal size distributions has been investigated and discussed. The results of both hexogen and octogen are compared.
\end{abstract}

\section{KEY WORDS}

Rocket propellants, Composite rocket propellants, Nitramine propellants, Hexogen, Octogen.

\section{INTRODUCTION}

Low vulnerability propellants (LOVA) and plastic bonded explosives (PBX) comprise a crystalline nitramines such as hexogen (RDX) or octogen (HMX). These are used to enhance performance, improve design characteristics and minimize signature. Nitramines also increase long time thermal stability, minimize thermal insulation problems in rockets and decrease pollution in the field [1-2].

The propellant must have rheological properties that permit flow into all parts of the motor case during casting [2]. If the flow is not adequate, voids or other defects can develop, causing an increase in the burning surface and may lead to detonation.

'Professor, Dpt. Of chemical engineering, Higher Technological Institute, $10^{\text {th }}$ of Ramadan, Egypt. 
To obtain good rheological properties, and to increase the solid loading in propellants and PBXs, especial grade RDX or HMX is needed [3].

Fine powders are usually prepared by grinding, spray drying, or by recrystallization. Grinding of nitramines is very dangerous due to its relatively high sensitivity to impact and friction [4], while spray drying towers are difficult to be designed and operated to produce such fine powders. Thus controlled recrystallization of cornmercially available hexogen and octogen is much more reasonable [5-7]. For obtaining fine hexogen and octogen crystals which are essential for improving the rheological properties and increasing the solid loading of nitramine propellants, three recrystallization methods are described.

\section{MATERIALS AND METHODS}

Materials:-

The materials and their sources are tabulated in Table 1.

Table 1.List of materials

\begin{tabular}{|c|c|c|}
\hline Material & Trade name & Sources \\
\hline Hexocen & RDX & ROF. UK. \\
\hline Octogen & $\mathrm{HMX}$ & ROF.UK. \\
\hline Acebne & $\mathrm{CH}_{3} \mathrm{COCH}_{3}$ & El Nasr Co. Egypt. \\
\hline Polysobate 80 & Tween-80 & Prolabo. France. \\
\hline Dimethy'sulphoxide & DMS & Aldrich Chem. Co. England \\
\hline
\end{tabular}

Sieving process:-

The distribution of particle size greater than 40 micron is determined by classifying it on a set of sieves placed on a shaking device (Retsch laboratory sieving machine model VS 1000.

The particles vith size less than 40 micron and the average particle size (APS) were determined by using Fisher subsieve sizer.

Experimentai lechniques:-

The fine hexogen (RDX) and octogen (HMX) obtained experimentally by recrystallization of the commercially available RDX and $H M X$, following three different methods of cry:tallization.

1- Dissolution of nitramines in solvents:-

54 grams ff RDX are dissolved in $100 \mathrm{ml}$ of acetone, while 68 grams of $\mathrm{HMX}$ are dissolved in $100 \mathrm{ml}$ of dimethylsulphoxide (DMS) at $60^{\circ} \mathrm{C}$ with gentle agitation using magretic stirrer.

2- Control of grcwth by stirring and cooling of supersaturated solutions:-

The particle size is contolled through vigourous stirring of dissolved nitramines 
at $(200,300,500,600,800$ r.p.m.), or by rapid cooling and all the other conditions affecting recrystallization process were kept constant for all cases,. Only natural cooling was used during stirring. Cooling recrystallization corresponding to rates of cooling equal to $2,3,5,6$ and $8 \mathrm{deg} . / \mathrm{min}$. Was done.

3- Special grade nitramine from dilution crystallizer:

The dissolved hexogen / octogen is kept without stirring and on natural cooling for 24 hours, evaporation of solvent took place and the solution is supersaturated. This supersaturated was then poured into $200 \mathrm{ml}$ of water at $25^{\circ} \mathrm{C}$. The precipitated crystals were filtered, washed and dried.

4- Controlling growth rate of crystals by using crystal habit modifiers:

10ppm of (Tween-80) were added to the dissolved solutions of RDX and HMX and agitated gently. The effect of variation agitation time (2,3,5,6 and 8 hours) on recrystallized nitramine was studied by analysing the resulting crystals.

\section{RESULTS AND DISCUSSION:-}

The results of the effect of changing the stirring speed at $200,300,500,600$ and 800 r.p.m. on the percentage of particles less than 40 micron (cumulative under size) of hexogen and octogen are tabulated in Table 2. And shown in Fig. 1.

Table 2.Effect of stirring speed on percentage of nitramine crystals (particle size is less than $\mathbf{4 0}$ micron

\begin{tabular}{|c|l|l|}
\hline $\begin{array}{c}\text { Stirring speed } \\
\text { (R.P.M.) }\end{array}$ & $\begin{array}{l}\text { Weight percentage of } \\
\text { crystals having particle size } \\
\text { less than 40 micron }\end{array}$ \\
\cline { 2 - 3 } & Hexogen & Octogen \\
\hline 200 & 31 & 35 \\
\hline 300 & 36 & 40 \\
\hline 500 & 45 & 52 \\
\hline 600 & 51 & 58 \\
\hline 800 & 65 & 68 \\
\hline
\end{tabular}

It is obvious that increasing the stirring speed, the particle size of the resulting crystals decreases and thus the percentage of crystals having particle size less than 40 micron is increased.

The results showing the effect of cooling rate (2/3//5/6/8deg./min.) on particle size distribution are tabulated in Table 3. and shown in Fig. 2. From these results one conclude that the percentage of fine nitramine is directly proportional to the rate of cooling. 
Table 3. Effect of cooling rate on percentage of nitramine crystals (particle size is less than 40 micron).

\begin{tabular}{|l|l|l|}
\hline \multirow{2}{*}{$\begin{array}{c}\text { Cooling rate } \\
\text { (deg./min.) }\end{array}$} & \multicolumn{2}{|l|}{$\begin{array}{l}\text { Weight percentage of crystals } \\
\text { having particle size less than } \\
40 \text { micron }\end{array}$} \\
\cline { 2 - 3 } & Hexogen & octogen \\
\hline 2 & 34 & 42 \\
\hline 3 & 37 & 46 \\
\hline 5 & 44 & 55 \\
\hline 6 & 47 & 58 \\
\hline 8 & 52 & 67 \\
\hline
\end{tabular}

Table 4. and Fig. 3 show the particle size distribution of crystals resulting from dilution crystallization of both hexogen and octogen.

Table 4. Cumulative particle size distribution for RDX and HMX recrystalized from dilution crystallizer

\begin{tabular}{|l|l|l|l|l|}
\hline \multirow{2}{*}{ D, microns } & \multicolumn{4}{|l|}{ Cumulative particle size distribution (\%) } \\
\cline { 2 - 5 } & RDX & HMX & $\begin{array}{l}\text { RDX with } \\
10 \% \text { CHM }\end{array}$ & $\begin{array}{l}\text { HMX with } \\
10 \% \text { CHM }\end{array}$ \\
\hline 300 & 95 & 98 & 97 & 98 \\
250 & 93 & 98 & 96 & 98 \\
210 & 84 & 90 & 95 & 98 \\
150 & 57 & 75 & 85 & 94 \\
12.5 & 43 & 63 & 72 & 85 \\
75 & 20 & 36 & 50 & 70 \\
50 & 12 & 21 & 36 & 55 \\
45 & 10 & 18 & 32 & 50 \\
30 & - & 10 & 11 & 40 \\
\hline
\end{tabular}

By the process of dilution crystallization one can obtain fine crystals (less than 40 micron) of high purity. Analysis of the fine crystals (less than 40 micron) is shown in Table 4., from which it is clear that fine crystals could be obtained in the range of 5 to 30 micron by dilution crystallization. 
Table 5. Cumulative under size analysis for hexogen Recrystallized from dilution crystallizer

\begin{tabular}{|c|c|}
\hline D,micron & Cumulative under size \\
\hline 28 & 98 \\
26 & 95 \\
24 & 91 \\
22 & 87 \\
20 & 81 \\
18 & 74 \\
16 & 65 \\
14 & 55 \\
12 & 42 \\
10 & 27 \\
8 & 15 \\
6 & 7 \\
4 & 2 \\
\hline
\end{tabular}

Table 6. shows the effect of addition of $10 \mathrm{ppm}$ Tween- 80 as crystal habit modifier (CHM) on percentage of particles having less than 40 microns diameter. Fig. 4 . Shows the influence of changing (Tween-80) time of agitation on particle size distribution. From these figures it is clear that the percentage of fine crystals increases with the increase of agitation time. The decrease of particle size is proportional to the increase of agitation time of $\mathrm{CHM}$ due to efficient spreading of $\mathrm{CHM}$ on crystal surface and. To obtain nitramine with suitable particle size distribution, it is necessary to optimize the time of agitation and the proportion of CHM.

Table 6. Effect of stirring time on percentage of nitramine crystals (particle size less than 40 microns) in the presence of CHM.

\begin{tabular}{|c|c|c|}
\hline \multirow{2}{*}{$\begin{array}{c}\text { Stirring time } \\
\text { (hours) }\end{array}$} & \multicolumn{2}{|c|}{$\begin{array}{c}\text { Weight percentage of crystals having } \\
\text { particle size less than 40 microns }\end{array}$} \\
\cline { 2 - 3 } & Hexogen & Octogen \\
\hline 2 & 30 & 36 \\
3 & 41 & 50 \\
4 & 51 & 61 \\
6 & 64 & 85 \\
8 & 73 & 95 \\
\hline
\end{tabular}




\section{CONCLUSIONS}

Increasing the stirring speed and cooling rate increase considerably the formed fine nitrarnine crysrtals (less than 40 micron). Also by the process of dilution crystallization ,fine crystals of high purity are obtained.Addition of crystal habit modifiers has a significant effect on particle size of produced crystals.

\section{REFERENCES}

[1] Hadhoud,M.K.,Haliem, O.A., Sadek,M.A. and Hassanien S.M.," Recrystallization of hexogen for PBX and lova propellant",Armed Forces Scientific research journal, No.44, pp 46-48, (1988)

[2] Hadhoud,M.K., Sadek,M.A. and Abdelkarim, S.M.," Performance characteristics of nitramine rocket propellants", $24^{\text {th }}$ ICT conference, Karlsruhe, Germany, pp43, (1993).

[3] Muthiah,R.M., Krishnaurthy,V.N. and Guptia, B.R., "Rheology of HTPB propellant, Effect of solid loading, Oxidizer particle size, and aluminum cortent",J. Appl. Polym. Sci., No.11, pp 44, (1992).

[4] MaCabe, W.L., Smith, J.C. and Hariott, P., Unit Operations Involving Particular Solids, Fourth edition, pp 804. (1985).

[5] Tavare,N.S. and Garslde,J., "Analysis of batch crystallizers", Ind. Eng. Chem. Process Des. Rev, No 10, pp653 (1980).

[6] Gallagher,P.M., Krukonis,V.J. and Vandekieft,L.J., " Gas anti-solvent recrystallization: application to the separation subsequent processing of RDX and HMX", Proc, $2^{\text {nd }}$ Int.Symp.SCF, Boston mass, pp45-48(1991).

[7\} Forter-Barth,U., Teipel,U. and Krause, H., " Recrystallization of HMX with compressed gases as anti-solvent", $29^{\text {th }}$ International Annual conference of ICT, Karlsruhe, Germany,pp67(1998). 

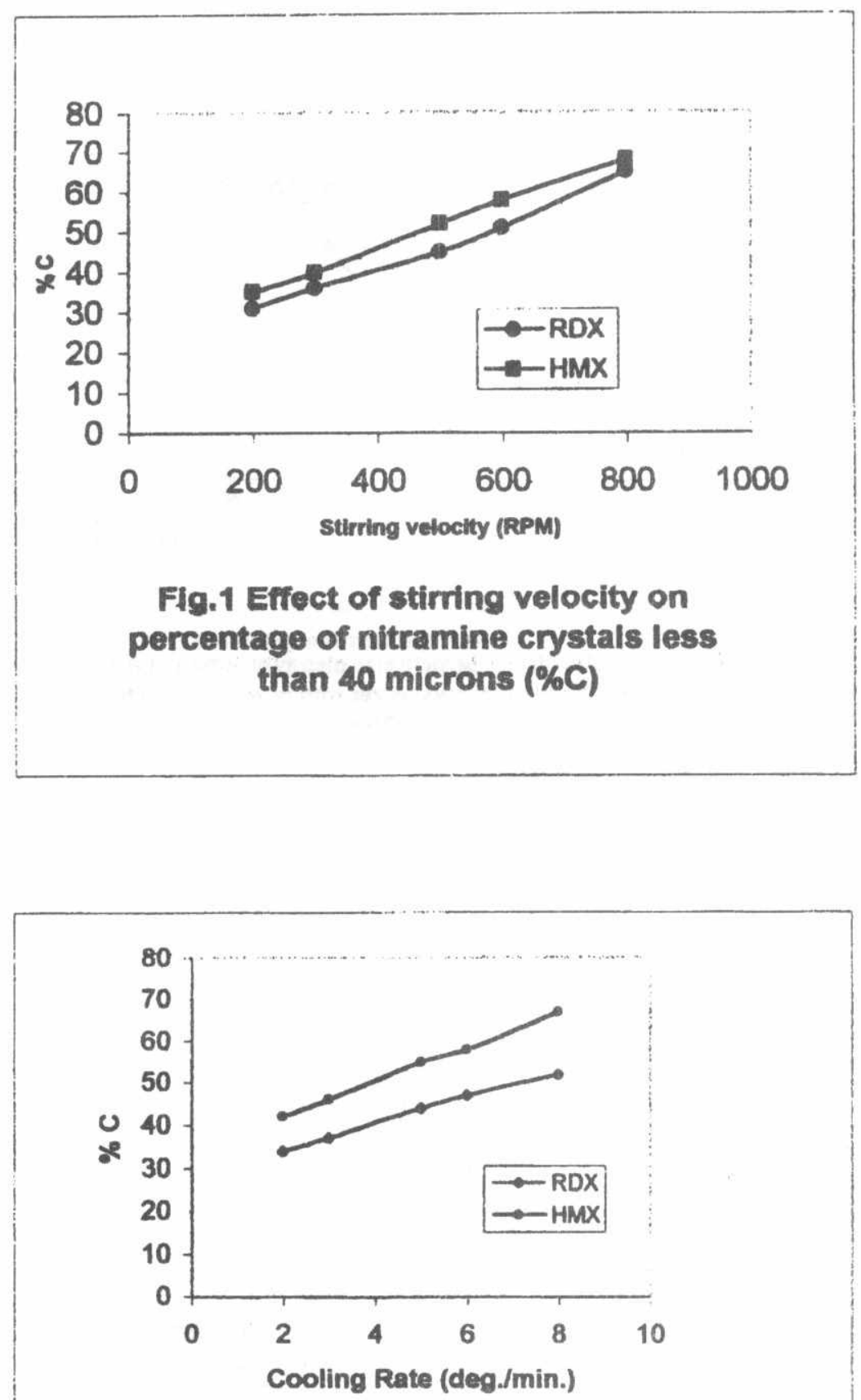

Fig.2. Effect of cooling rate on Percentage of nitramine crystals less than 40 micron $(\% \mathrm{C})$ 

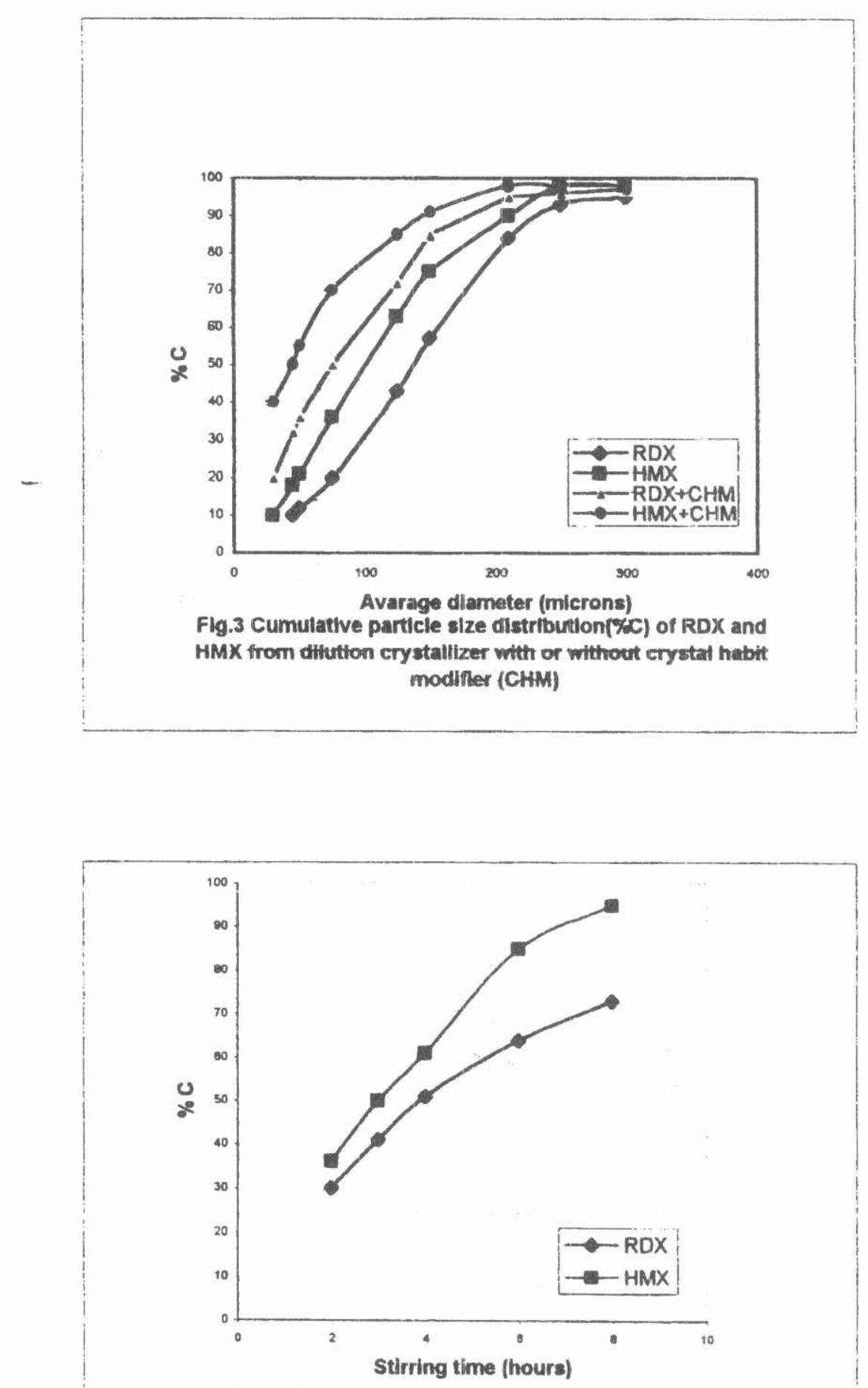

Fig. 4 Effect of stirring time on percentage of nitramine crystals less than $\mathbf{4 0}$ micron $(\% \mathrm{C})$ In the presence of Tween-80 as crystal habit modifier 